\title{
The implications of the precautionary principle for biological monitoring
}

\author{
M. MacGarvin \\ Consultant to Greenpeace International; Keizersgracht 176, 1016 DW Amsterdam, \\ The Netherlands \\ and \\ Dpt. of Zoology, University of Aberdeen, Culterty Field Station; Newburgh, Ellon, \\ Aberdeenshire AB41 OAA, Great Britain*
}

\begin{abstract}
Marine biological monitoring programmes frequently attempt to determine "safe" levels of contamination, based on assumptions about the assimilative capacity of the environment. This paper argues that such assumptions lack scientific rigour, and do not form the basis upon which a precautionary policy can be built. It notes the problems associated with assessing toxicological effects, but centres its attention on the crucial (yet far less discussed) weaknesses in theoretical ecology that make it extremely unlikely that biological monitoring can determine safe levels of contamination that leave ecosystems unaffected. It is argued that many marine biologists, if pressed, would concede these shortcomings but believe that, in the face of the technical difficulties and high costs of pollution prevention, we have no choice but to use such methods. This paper argues, with examples, that pollution prevention, often with considerable economic savings, is becoming a reality for even the most problematic substances. The difficulty is that the development of "clean production" methods lie outside the sphere of interest of those carrying out monitoring, so that measures that attempt to determine safe levels of contamination continue to be advocated. This gulf needs to be bridged so that the continuation of monitoring programmes that are part of dilute and disperse policies become regarded as inappropriate, indeed unethical. The paper concludes that this does not mean the end of marine monitoring. Instead, reliable methods for assessing physical levels of contamination will be required to determine whether the reduction targets set - as part of the introduction of clean production - are being met. Formidable difficulties will remain, requiring a precautious approach. Nevertheless, monitoring will no longer carry the burden of attempting to demonstrate that a particular level of environmental contamination is safe, which is currently destroying its scientific credibility.
\end{abstract}

\section{INTRODUCTION}

Present environmental policy in the countries surrounding the North-East Atlantic is a chimera; an ambiguous monster in part made up of old attitudes that assumed the environment to be largely capable of absorbing the effects of our actions, in part a new precaution that recognises that we cannot fully predict the result of such actions, but accepts that they can seriously damage the environment. This reflects a deeper change in

\footnotetext{
- Present address for all correspondence
} 
society, which is shifting from regarding nature as a resource where human interests are paramount towards a view that requires protection of the natural environment, either out of enlightened self-interest or, increasingly, for its own sake.

This transition is occurring in all parts of society. There has never been greater interest in the environment, and the "green consumer" has become a significant force in the market. It has also influenced many professionals involved in marine protection, who have argued in favour of sweeping changes in the international and national regulatory framework. As a result, new international conventions, such as the Convention for the Protection of the Marine Environment of the North-East Atlantic, now legally require countries to adopt policies that recognise "the inherent worth of the marine environment" (Oslo \& Paris Commission, 1992a). In philosophy, "environmental ethics" or "ecophilosophy" has grown from the 1970 s, when participation could be regarded as grounds for refusal of university tenure (Hargrove, 1987), to now, where it is one of the most rapidly developing and stimulating areas of philosophy. A sound philosophical foundation, capable of popular expression, is essential if environmental concern is to be translated into effective action (Kinne, 1994), but a review lies outside the scope of this paper. Instead, reference is made to two key works. The first, Naes (1989), summarises the work that did much to make ecophilosophy "respectable", stimulates discussion and sets out Naes' own proposals. The second, Fox (1990), evaluates and expands these concepts.

This present paper addresses an issue specific to marine biologists involved in environmental protection. It argues that the failure to analyse the weaknesses in monitoring programmes (and, for that matter, in fisheries biology and habitat protection) means that they lack scientific rigour, and do not form the basis upon which a precautionary environmental policy can be built. This paper concentrates on just one aspect of monitoring - that of attempting to determine "safe" levels of contamination in marine ecosystems. It notes the problems in assessing the toxicological effects of a complex mixture of chemicals, but centres its attention on the crucial (yet far less discussed) weaknesses in theoretical ecology that make it extremely unlikely that biological monitoring can determine safe levels of contamination that leave ecosystems unaffected.

It is argued that many ecologists, if pressed, would concede these shortcomings but believe that, in the face of the technical difficulties and high costs of pollution prevention, we have no choice but to use such methods. This leads to the second area addressed here because it is now clear that pollution prevention, often with considerable economic savings, is becoming a reality for even the most problematic substances. The difficulty is that these developments lie outside the sphere of interest of those carrying out monitoring, so that measures that try to determine safe levels of contamination continue to be advocated. This paper attempts to summarize enough detail of "clean production" methods to demonstrate that they are ready to be placed at the centre of environmental policy, obviating the need for monitoring programmes that attempt to determine the assimilative capacity of the environment.

The paper concludes by arguing that this does not mean the end of marine monitoring. Instead, reliable methods for assessing physical levels of contamination will be required to determine whether the reduction targets set - as part of the introduction of clean production - are being met. 


\section{THE POLITICAL CONTEXT}

In the 1960s and 70 s, environmental policy treated the marine environment as a resource, whose exploitation was limited only by considerations of the effects of one group of people upon another. Thus, fisheries policy was predominantly concerned with the distribution of catch quotas, and consideration of the effects on other components of the marine food web was excluded. Similarly, the effects of pollution on marine species was considered mainly in the context of whether the levels of contamination posed a threat to human consumers. In all such considerations the burden of proof of environmental damage rested on the environment.

However, this permissive principle was shaken by a sequence of unpredicted events (pesticides, PCBs, CFCs and the ozone hole, eutrophication), coupled with the discovery that contamination was by no means rapidly diluted, and dispersed pollution from inshore waters and coastal seas (Stebbing, 1992). It led to the emergence of the precautionary principle, which first appeared internationally in the First Ministerial Conference on the North Sea, held at Bremen in 1984, and which was used at the Second (1987) and Third (1990) Conferences to justify cuts in contaminants such as synthetic chemicals, heavy metals, and nutrients, and the cessation of practices such as ocean incineration, because the burden of suspicion against them made it prudent to limit or prevent such activities.

The precautionary principle is far more than a plea to add an extra magin of safety to old practices (Sperling, 1986). Once it is accepted that we cannot expect, for example, to predict "safe" levels of contamination, then it inevitably follows that a precautious policy can hardly be based on practices that allow the discharge of substances into the environment, followed by monitoring to see if they have an effect. However, in practice, it has been very different. What has happened is that elements of precaution have been grafted onto a body of policy still based on assimilative capacity. The result is a contradictory mess. Policy makers have been slow to set in motion a thorough reappraisal of environmental policy in the light of the need for precaution. Advocates of precaution have also failed to explain in sufficient detail the logic behind their case, and its implications.

The result has been much uncertainty amongst pollution scientists about the implications of the precautionary principle for their work. This has meant that, while the scientific justification for assimilative capacity policy has largely evaporated over the last decade, much of the expertise of marine scientists is still tied up pursuing a goal that cannot be met.

\section{BIOLOGICAL MONITORING: A HOUSE BUILT ON SAND}

Determining the effects of human activities on marine species and ecosystems has always been regarded as extremely challenging. As a result, the implementation of biological monitoring programmes by bodies such as ICES (International Council for the Exploration of the Sea) and PARCOM (Paris Commission) lagged well behind those for the measurement of the levels of contaminants and the determination of "safe" levels of contamination in marine foodstuffs for human consumption (McIntyre \& Pearce, 1980; ICES Advisory Committee on Marine Pollution, 1985; MacGarvin \& Johnston, 1988; Stebbing et al., 1990; Hoogweg et al., 1991; MacGarvin \& Johnston, 1993). Similarly, it 
explains the search for methods that could be applied at a biochemical or physiological level, in the hope that more contentious and labour intensive ecosystem monitoring could be avoided.

Yet these attempts to eliminate ecology have many problems. Again, it is not the intention of this paper to delve deeply into these, which have been well noted at the 1992 Helgoland Symposium, as elsewhere (Johnston \& MacGarvin, 1988; Johnston et al., 1990a; Johnston et al., 1990b; Smith \& Johnston, 1992; Johnston et al., 1993). However, the limitations of generalised techniques, such as measurements of mixed function oxidases, MFOs, were once more highlighted. And even at best such techniques, as well as general surveys, for instance of the worrying levels of fish embryo malformation recorded in the North Sea, can only indicate that changes have occurred, not their cause. Such research is therefore caught between two impractical situations - either to know that an effect is occurring, and depend on a large measure of luck to determine the cause, or to try to assess the effects of thousands of chemicals, something that is out of the question given the cost of at least $\$ 10000$ per chemical to test bioconcentration and acute toxicity for a few organisms, and $\$ 100000$ to $\$ 1000000$ or more for a more detailed (Nirmalakhandan \& Speece, 1988) but still uncertain assessment.

Therefore, while information on changes in the biota and the ecology of areas such as the North Sea is useful, because it highlights the possibility of change due to human activities, this is more appropriate as a spur to politicians than as part of a fail-safe environmental policy. Physical scientists and biologists alike now emphasise that the models and tests of the effects of contaminants in the marine environment are crippled by a lack of information on the ecological interactions that maintain ecosystems.

\section{ECOLOGY - THE ACHILLES HEEL OF MONITORING}

The desire to side-step ecology is understandable, but inadmissible. Indeed, even the determination of energy and other flows through the food web does not provide the relevant information to predict ecological effects. Instead, it demands long-term detailed observation and the experimental manipulation of populations (Underwood, 1985; Simberloff, 1988; Kinne, 1994). For instance, a species such as the blue-rayed limpet Helcion pellucidum makes up a minute portion of the biomass of European kelp forests. But they bore into the holdfasts of kelp, weakening them so that they are prone to detach from the rock and subsequently die. As a result any factor that influences the abundance of such animals may have drastic effects on the kelp, community as a whole, even though their biomass may still be insignificant. Similarly, the increase of nutrients in coastal waters is very likely responsible for the massive increase of Phaeocystis, the algae responsible for the masses of foam that disfigure many North Sea beaches (Lancelot et al., 1987; Cadée, 1990). Because species of zooplankton, such as copepods, have feeding preferences for different species of phytoplankton (Davies et al., 1992), and because they in turn are important links in the marine food web, the change in Phaeocystis abundance could well have important implications for coastal North Sea ecosystems in general and for fisheries in particular. Yet even a partial untangling of the effects on the food web is a slow process requiring dedicated, painstaking work (Hansen, 1994).

Unfortunately, even sheer hard work does not guarantee success. In fact the expecta- 
tions of theoretical ecology in general and marine ecology in particular have been sharply reduced in the last few years. This leads to the central point of this paper - that our understanding of ecosystems such as the North Sea is so poor that attempts to determine the effects of contaminants by monitoring are unlikely to succeed in all but the most obvious cases. The uncertainty and soul-searching that has dominated theoretical and "pure" marine ecology since at least the mid-' 80 s has implications which have been surprisingly slow to trickle through to applied sciences such as monitoring. At least four relevant areas can be identified; the confounding effect of many different human activities, the downward assessment of progress in marine ecology, the reduced expectations of theoretical ecology in general, and the uncertainties introduced by the possibility of chaotic population dynamics. Any one of these has crippling implications for our ability to predict the effect of our actions; taken together they remove the scientific justification for basing pollution policy on the attempt to find "safe" levels of contamination.

\section{Confounding effects}

Modern ecological methods emphasise the importance of rigorous experimental and statistical design that allow different hypotheses to be isolated and tested (Peters, 1991). High natural variability in areas such as the North Sea make it extremely difficult to determine human effects (Gunkel, 1994), and to make matters worse many different human activities take place. But research by different groups almost invariably concentrate on single issues, such as fishing or contamination, without attempting to untangle the interactions. In addition, research is confounded because the gathering of basic information during this century has been coupled with unprecedented and increasing human effects. As a result we can have no clear idea of how the natural ecosystem would function, nor do we have true controls with which to compare areas affected by human activities.

\section{Marine ecology reassessed}

Toxicologists assume that it is possible to monitor just a few species, using these as indicators for the whole ecosystem. Up until the early ' 80 s the principle could perhaps be partly supported by research on temperate rocky intertidal areas, whose population dynamics were regarded as the best understood of any marine habitat (Underwood \& Denley, 1984). This research indicated the existence of just a few "keystone" species, where changes in their population levels resulted in a cascade of effects throughout the food web. Alteration of the population levels of most other species, it was thought, had little effect (Dayton, 1984). This concept of keystone species was nested within a wider model of rocky shore community structure that predicted that, while physical survival would be the most important factor on exposed coasts, predator control would be the most important force in sheltered areas, with competition between species on the same trophic level playing the most important role at sites with intermediate physical exposure (Menge \& Sutherland, 1976). It was also expected that research would reveal keystone species in other compartments of the marine ecosystem.

However, keystone species need not be particularly common or obvious; instead, their discovery requires a detailed programme of population manipulation and exclusion. 
As a result, the number of established cases remains relatively small, albeit with a global distribution (Paine, 1971; Dayton et al., 1974; Menge, 1976; Lubchenco \& Menge, 1978). The original work of Paine (1966) in an intertidal area in Washington State remains the most well-known. Here the exclusion of the starfish Pisaster ochraceus resulted in a dramatic sequence of changes, over the space of two years, from a diverse community to one dominated by the mussel Mytilus californianus. But even this work does not mean that a species such as Pisaster can be used as a universal indicator - later work showed that it is, in the words of Paine (1980) "just another species" at another location because of the absence of $M$, californianus.

On soft-bottomed habitats the type of manipulation experiments that are necessary to explore community regulation are far more difficult, and there are very few candidates for keystone species, such as the starfish Solaster dawsoni that feeds on sea pens in the subtidal areas of Puget Sound, Washington (Birkeland, 1974). Meanwhile, the difficulties of experimental manipulation in open water is an important reason why ecologists such as McGowan \& Walker (1979) and Dayton (1984) were forced to concede that little progress has been made in resolving the "paradox of the plankton" (that vast numbers of species apparently find ways of coexisting in this simplest possible of habitats), pointed out over 30 years ago by Hutchingson (1961). And while the current emphasis on physical processes in planktonic ecology gives another dimension to the analysis (cf. Mann \& Lazier, 1991), it is not clear that this guarantees a resolution of the paradox.

Given these difficulties, the few species used for biological monitoring are not keystone species. Instead, they are selected because they conveniently absorb contaminants (mussels), are quick and easy to test (the oyster bioassay) or need in any case to be monitored for human health (commercial fish species). While the exclusion of keystone species is understandable, it means that monitoring programmes intended to protect marine habitats do not have a firm scientific foundation.

Moreover, the assumption that most non-keystone species play minor roles in ecosystems and, by implication, can be ignored by biological monitoring programmes must be questioned. Species are often innocuous because they are kept rare by predators, parasites or disease, and can increase dramatically when introduced into a new habitat free of such constraints, as a host of terrestrial, freshwater and marine examples testify. It is possible that contaminants (or other human activities) could also adversely affect the dynamics, resulting in outbreaks of species which then disrupt the ecosystem. More complex effects could occur involving a web of species. In either case, work based on individual species may give no hint of human involvement.

Apart from the problems associated with the search for keystone species, the synoptic model of community structure of rocky habitats, structured along a gradient depending on physical exposure, has also been found wanting. A growing unease that its conclusions were simplistic were given focus by Underwood et al., (1983) and Underwood \& Denley (1984). Their work on intertidal barnacles indicated that the number of adults was determined by the number of larvae that survived their plankton phase and settled onto the rocks - which varied hugely from one year to the next. Perhaps the most remarkable feature is that many others before were aware of such huge annual variation in rocky shore recruitment, but had instead simply seen it as a nuisance to be filtered out of the results, rather than the key feature. The result of this and other work (Gaines \& Roughgarden, 1985: Lewin, 1986; Roughgarden, 1989) is that the ecology of rocky shores, 
once considered to be a show-case for marine ecology - indeed all ecology - has gone back to reconsider basic principles (Underwood \& Denley, 1984). There are lessons here for monitoring, notably the way in which the momentum built up by a theory kept it alive long after the weight of evidence was against it. It also shows how it has proved impossible to isolate research in one compartment of the ecosystem. Instead, understanding of the rocky shore - once regarded as the easiest to study - is intractably linked to events in the plankton, a graveyard for ecological aspirations.

\section{Theoretical ecology}

The reappraisal taking place amongst marine ecologists is just part of a general stock-taking by theoretical ecologists since the subject changed direction in the 1950s to adopt a more rigorous scientific and mathematical approach. The outcome has been a drastic lowering of expectations.

One key area for both pure and applied research during this period has been the search for density-dependent mortality. These are those causes of death that must regulate the population of a species if it is to have a characteristic level of abundance. They kill proportionately more of the population if it rises above this level, and relax their pressure when the population falls. Comprehensive data, systematically accounting for and distinguishing between all causes of death over a number of generations sufficient to encompass the range of population densities, is essential. Without it the interactions between density-dependent and independent causes of mortality cannot be determined. Nor can accurate predictions be made of future population levels - including those resulting from human perturbations.

Given the amount of effort that has been spent gathering data on marine fish, particularly in the North Sea, some may be forgiven for thinking that here at least biological monitoring has a good foundation. Unfortunately the truth is rather different. The size of each generation of marine fish is largely determined between the release of eggs and the recruitment of young adults into the fishing stocks, a period when it is extraordinarily difficult to gather information. As a result, population predictions have proved highly inaccurate. Even within the field, Wootton (1990) notes "it takes an act of faith to take the resulting curves seriously", and Rothschild (1986) has drawn attention to the need for a radical reappraisal of fisheries biology methods and goals. Theoretical ecologists from other fields, knowing the difficulties in gathering sufficient information even under the most favourable circumstances, view with incredulity the attempts of fisheries biologists to predict population fluctuations. Peters (1991) speaks for many when he says "Fisheries management is so accustomed to inaccuracy in its basic models that striking differences between model and observation are scarcely noted ... Nevertheless, fisheries biologists fit data to models that are clearly inaccurate and make decisions on that basis". Few others have commented as directly as Peters, but it is significant that population and theoretical ecologists outside fisheries biology largely ignore their work, as is evident from the lack of citations.

The difficulty of following discrete populations extend to marine species other than fish. The result has been the creation of a rich mass of incomplete and conflicting data, capable of inspiring faith in any number of theories, yet from which it is impossible to draw firm conclusions. However some clues might be gained from terrestrial systems. 
They, too, have their fair share of confusing evidence. Fortunately, however, some species, particularly amongst insects, lead lifestyles that are amenable to the systematic attribution of the causes of death over many generations that is necessary for an analysis of density-dependent mortality (Caughley \& Lawton, 1981) - 19 years in the case of a winter moth Operophtera brumata population living in an Oxfordshire wood, which formed one of the earliest yet most comprehensive studies (Varley et al., 1973).

However, it became clear that even work of this type was still severely limited when it came to predicting future trends. Although the studies could sometimes account for an impressive proportion of deaths, the remaining uncertainties rapidly multiply over a projection of just a few generations, creating a huge degree of error compared to events in real life - as demonstrated by Harcourt's (1971) study of the potato-infesting Colorado potato beetle Leptinotarsa decemlineata. The size of this error might be reduced, for instance, by having a better understanding of the factors that made the numbers of natural enemies fluctuate, with the result that they failed to bring the original species back to its mean population size. But this would require a cascade of studies similar to that on the original species, and a vast increase in work that would result in only a slight improvement of the estimates. Problems such as these indicated that all attempts to predict populations would rapidly come up against a barrier that no additional funding or new techniques could overcome.

For theoretical ecologists, unlike applied biologists, this was not too much of a blow. They felt they had what they needed $i$ an understanding in principle of how population regulation worked. Rather than pursue the diminishing returns of further such studies, by the 1970 s much of their effort was directed instead towards the deeper understanding of individual aspects of density-dependent mortality, such as the searching behaviour of natural enemies or the effects of habitat heterogeneity, using a combination of mathematical models, laboratory and field studies (e.g. Caughley \& Lawton, 1981; Hassell, 1981). A variety of species were used, selected for ease of study of the particular character of interest. Many felt that reasonable progress has been made, given the immense complexities of the subject.

However, the 1980s saw an increasing sense of frustration at the apparent inability to produce a grand unifying theory. The reassessment of rocky shore ecology has been just a small part of this storm. Heated debates occurred, at first over the relative importance of competition or natural enemies in the regulation of populations, and then increasingly over flaws in experimental design, statistical analysis, and the formulation and testing of hypothesis in general (Strong et al., 1984; Roughgarden et al., 1989; Peters, 1991). Underlying this has been a more profound mood change in theoretical ecology, a feeling that the new methods have not delivered the goods expected of them 30 years ago. Major journals now carry editorials asking why ecology, unlike biochemistry of the physical sciences, has not solved the problems it set itself (Lawton, 1991). Other influential ecologists such as Roughgarden (1989) and Kareiva (1989) have concluded that the science lacks solid foundations, and that for the time being ecologists should give up any idea of forming grand unifying theories, and concentrate instead on far more narrowly defined studies.

The fact that theoretical ecologists, working in far easier fields than marine ecology, are now asking such searching questions of their methods highlights how unreasonable it is to expect that we can predict the effect of human actions upon marine ecosystems with any accuracy. 


\section{Chaos}

The possibility of chaotic population fluctuations is yet another unwelcome complication for applied scientists. Assessing the significance of chaotic population fluctuations will be formidable, because it will require new data, carefully gathered, extending over perhaps hundreds of generations. No research programme, however vast, can do anything, it seems, to speed the gathering of such information.

The uncertainties are highlighted in an analysis by Godfray \& Blyth (1990) of the population fluctuations of copepods. The data was gathered by the Continuous Plankton Recorder (CPR) in the seas around the British Isles for over 40 years - one of the most comprehensive data sets available. Yet, sophisticated mathematical decoding techniques were unable to determine whether the fluctuations in their numbers during this period were due to random events, or a simple (but unknown) cause that resulted in chaotic fluctuations. The run of data is simply too short for such techniques. The implication is that one might have to gather data for hundreds of years before being able to (possibly) determine whether a factor such as increased nutrient concentrations has an effect on an ecosystem!

The mobility of the CPR introduces uncertainties about whether the same population is being sampled. But data from fixed sites does not necessarily resolve this problem. Other difficulties exist, such as sampling taking at a fixed time of day (missing diurnal migrations or tidal effects) and changes in recording methods. In brief, the need to unravel the possible influence of chaotic fluctuations reduces even further the remote hope of predicting the effects of human actions upon marine ecosystems.

\section{A council of perfection?}

Clearly there are many intractable problems associated with biological monitoring. It seems inevitable that any debate will reach a point where those arguing for such methods acknowledge the imperfections and weaknesses, but state that we have no choice but to use such methods, because the alternative, i.e. pollution prevention, is impractical. The lack of scientific rigour is conceded, but to continually highlight this appears to be a council of perfection.

However, the pressing need for pollution prevention is simply illustrated. The assimilative capacity of the environment is impossible to define in any precise way. But the opinions of scientists, based on what is known already, is revealing. There is, it seems, a growing view that it is imprudent to have any level of synthetic, artificial, compounds in the marine environment. But what of the more thorny issue of anthropogenic inputs of naturally occurring substances? Given that they have their greatest concentrations and effects in rivers, estuaries and coastal zones, where historic burdens are also available for remobilisation (cf. Dickson, 1987; Eisma \& Irion, 1988), it might be expected that the range of debate for no-effect input levels for areas such as the North or Irish Seas as a whole will lie between zero and a few percent of natural inputs. This is because of the large natural inputs to these seas as a whole from the Atlantic. Yet the actual levels of metals and nutrients entering these seas are far higher - often $10,25,50 \%$ or more, of natural levels (Gerlach, 1988; Salomons, 1988; Irish Sea Study Group, 1990). It therefore seems clear that a debate about no-effect levels of naturally occurring substances is largely irrelevant; whatever the outcome, it is clear that current production practices and 
product usage will have to change drastically if we are serious about protecting marine ecosystems. It will require a switch to pollution prevention strategies and closed loop production processes that far exceeds those currently required by national and international programmes.

\section{THE POSITIVE ALTERNATIVE}

Recent developments in pollution prevention mean that it now has far greater potential than those outside the field are usually aware of. The unfortunate result of this lack of communication is that marine scientists, for example, continue to attempt to determine safe contamination levels even when there is a more precautious alternative. This gulf needs to be bridged so that the continuation of monitoring programmes that are part of dilute and disperse policies become regarded as inappropriate, indeed unethical.

These new developments come under the banner of "clean production" (Baas et al., 1990), which is a super-set of clean technology that emphasises that pollution prevention may involve, for instance, new operating practices as well as new technology - although in practice the distinction is often blurred. Clean production grew out of the realisation of two points; that pollution prevention is the only practical means of implementing the precautionary principle, and that earlier attempts at prevention, such as no- and lowwaste technology, were seriously flawed because they concentrated only on pollution caused by waste from manufacturing processes. Moreover some of these technologies created extremely concentrated, hazardous waste. This resulted in disposal problems and helped create an undesirable toxic waste trade, where waste is shipped to countries with the least stringent disposal standards (cf. Puckett, 1991).

Clean production methods can be summarized as those which meet the needs of society - for food, water, energy, transport, goods and services - without damaging the natural world or risking the health of workers or the wider community. They cover all aspects of a product's life cycle - design, raw material extraction, manufacture, use and eventual fate. They aim to avoid the use or manufacture of hazardous products or waste. They are designed to employ only reusable and renewable materials and to conserve energy, water, soil and other raw materials.

Clean production has been recognised since 1989 by the United Nations Environmental Programme (UNEP Governing Council, 1989), and in UN maritime agreements, such as the London Dumping Convention (Ad hoc group of experts on annexes to LDC Convention, 1992), whose provisions have binding force on North Sea states, as elsewhere. Similarly the new Convention for the Protection of the Marine Environment of the North-East Atlantic, agreed in Paris in September 1992, contains many of the elements of clean production (Oslo \& Paris Commission, 1992a).

So much for the theory. More important is that there are now many examples showing how clean production can be implemented by problem industries. A crucial element is the auditing of the materials used and produced by production process. This does not mean the superficial "environmental audit" produced by some companies as a public-relations exercise, but the preparation of a systematic, quantitative, chemical mass balance of the materials involved. Such methods received a boost when the United States EPA produced a waste minimisation handbook (US Environmental Protection Agency, 1988) which developed the techniques and provided step-by-step worksheets in a form 
appropriate for normal companies. These methods have since been developed in Europe, for instance as part of the Dutch PRISMA project (de Hoo et al., 1991).

The potential of auditing is illustrated by surprising inefficiencies even in major companies (Sarokin et al., 1985). It took stricter regulations for solvent emissions in the US for one Exxon plant to realise that floating ceilings on storage tanks would result in major financial benefits by preventing annual losses of over 300 tonnes of chemicals. Without regular audits broken equipment can also go undetected - a faulty valve, leaking 180 tonnes of cumene per year at a cost of $\$ 100000$, was only discovered at USS Chemicals when an employee finally chanced to smell the characteristic odour. And there can be huge variations in efficiency; for example, of two US plants using phenol, Exxon used 2600 tonnes per year and lost 2 tonnes $(0.08 \%)$ while Rhone-Poulenc used 1600 tonnes and lost $17 \%$, over 272 tonnes. Similarly, a survey of small and mediumsized companies in Copenhagen (Larsen \& Olsen, 1989) showed huge differences in waste production levels between companies producing the same products and services. Such findings are typical. Systematic auditing offer a rapid means of significantly reducing pollution levels.

A co-operative venture between companies from "problem" sectors of industry in the town of Landskrona, Sweden, and the TEM department of Lund University illustrates the steps in introducing clean production (Backman et al., 1991). TEM would first hold a workshop with senior management (whose support is essential) to discuss clean production concepts and case histories from similar companies. TEM and company technicians would then co-operate in producing a mass balance of materials used and produced during manufacture. This revealed problem areas. TEM would then propose clean production options, which the company would then evaluate and adopt where possible. Further auditing would mark the start of a new cycle. The introduction of cleaner production processes not only resulted in the reduction of pollution: companies found that they could often make considerable financial savings from reduced losses of raw materials, from money saved from increasingly expensive waste disposal costs, and by avoiding costs resulting from ever tougher environmental regulations on traditional processes.

As a result of the programme a major lighting fixtures manufacturer at Landskrona, Thorn Järnkonst $A B$, was able to switch from using mineral lubricating oils during the machining of metal - which was then cleaned using organochlorine solvents - to vegetable-based oils that could be removed using a mild alkali rinse. This avoided the need to meet increasingly stringent organochlorine emission standards, and saved the disposal costs of exhausted mineral oils. They also switched from using organochlorine solvent based paints to powder-based paints for $95 \%$ of production. Overall these not only resulted in cleaner production processes but also resulted in annual savings of $\$ 460000$. Other examples from Landskrona include a printing works that switched to water-based inks, significantly reduced pollution from an electroplating firm as a result of improved housekeeping, and the discovery by a chemical plant that $3 \%$ of the matrix material produced for water-based emulsion paints was being discharged with waste water, resulting in annual losses of hundreds of thousands of dollars.

Elsewhere bodies such as the Technical Institute of Copenhagen (Christiansen \& Kryger, 1989, the Erasmus University at Rotterdam, the University of Amsterdam and the Netherlands Organisation of Technology Assessment (all involved in the Dutch PRISMA 
project) along with many other initiatives, have demonstrated that there is no shortage of cleaner production methods. For example, for organohalogens, one of the most problematic chemical groups, it is now clear that they are suitable candidates for the substitution for all major applications (Rosander \& Fredman, 1989; Bundesminister für Umwelt, Naturschutz und Reaktorsicherheit, 1992), including degreasing, dry cleaning, paint and print removal, their use as solvents by industry (including CFCs used by the electronics industry), as foaming agents, in PVC and other plastics, for cooling, and in the manufacture of medicinal pills, glues, paints, lacquers, lubricants, rust preventers and removers, furniture polish and fabric spot-removers. Even more remarkable has been the dramatic European switch to chlorine-free paper, led by consumer pressure in Scandinavia and Germany (Pearson, 1991). This resulted in a fall in organochlorine pollution from Swedish pulp and paper mills by $50 \%$ in three years (Swedish Environmental Protection Agency, 1991). Companies that had the foresight to install chlorine-free bleaching processes benefited enormously.

\section{Implementing clean production}

Of course there are shortcomings in the current implementation of clean production. Companies still rarely assess those stages in the life cycle of a product that take place outside the factory gates (Dieleman et al., 1991), (even though, as Lindhquist [1989] points out, in countries such as Germany and Sweden, companies have a legal responsibility for the ultimate fate of their products), and many measures adopted are far from perfect - cleaner production rather than clean production.

But the most important obstacle until now has been neither the lack of suitable processes or higher costs, but that of inertia, in particular the failure of governments to promote clean production policies (Huisingh, 1989). The importance of legally binding requirements is crucial. Many of the examples cited above resulted in considerable financial gains for the companies, yet it was impending regulations that prompted their interest in these methods. Legislation for companies needs to be accompanied at national and international level by comprehensive plans to eliminate problem groups such as organohalogens, rather than the partial and ineffective measures taken at present. This will require the compilation of a mass balance of inputs and outputs within and between countries, information which at present is surprisingly scarce.

For these reasons the new Convention for the Protection of the Marine Environment of the North East Atlantic could be a very significant development (Oslo \& Paris Commission, 1992a). This legally binding document commits the countries in this region to the reduction and elimination of substances that may cause severe problems in the marine environment, rather than of pollution by such substances which, being impossible to define, resulted in endless argument and prevarication. There is a requirement, and a mechanism, for establishing clear goals and timetables for phase-outs and product bans. Meanwhile, the accompanying action plan (Oslo \& Paris Commission, 1992b) highlights organohalogens, and requires the elimination of those that can be substituted by other materials. This is true of a least all significant uses, so this appears to mark the beginning of the end of organohalogen production. This, and the many other measures set out, will only be possible by the implementation of techniques associated with clean production. This convention marks a significant point in the metamorphosis of the 
environmental chimera into a consistent, precautionary, policy. And among the many implications it and similar developments have are those for marine monitoring.

\section{THE FUTURE OF MARINE MONITORING}

Clearly, for the reasons already advanced, attempts to establish safe levels for the ecosystem are inadmissible; logic dictates that the precautionary principle surely applies as much to methods that are open to "reasonable grounds for concern" (Oslo \& Paris Commission, 1992a) as it does to the contaminants themselves. But does this mean that the implementation of a precautionary environmental policy would mean that there would be no monitoring at all?

The answer is no. Monitoring should continue, but with a different purpose. Pollution prevention measures are usually phased in, with a series of reduction targets. Until now assessment of whether these targets are met are largely based on dubious, incomplete, incompatible and out-of-date calculations about the levels of inputs believed to enter areas such as the North-East Atlantic by various routes (e.g. Paris Commission, 1991). Instead the assessment should be based on measurements made in the marine environment itself. If they show that reduction measures are falling short of the target, then this will require a intensification of the steps being taken to reduce contamination.

This information, coupled with that from product auditing, allowing a mass balance to be calculated, will play an important, albeit subsidiary, role in the implementation of clean production methods. There will still be a need for precaution, as a considerable degree of error will be present due to inadequacies in analytical (Johnston \& MacGarvin, 1989) and statistical methods (Peterman \& $M^{\prime}$ Gonigle, 1992). This will require monitors to err on the side of caution when faced with a range of estimates. Nevertheless monitoring will no longer carry the impossible burden of attempting to demonstrate that a particular level is safe, which is currently destroying its scientific credibility.

Acknowledgements. Greenpeace International generously provided funding and assistance, although the views expressed here are those of the author and not necessarily those of Greenpeace International. Thanks are also due to the German Minister for Research and Technology who funded attendance at the Helgoland Symposium at which an earlier version of this paper was given. Stimulating discussion and other help have been rendered by many, including L. Beale, A. Booth, B. Edwards, P. Johnston, I. McCrea, L. Riley \& K. Stairs.

\section{LITERATURE CITED}

Ad hoc group of experts on annexes to LDC Convention (Ed.), 1992. Report of the 4 th meeting. (LDC/SG 15/2 Annex) LDC Secretariat, London.

Baas, L., Hofman, H., Huisingh, D., Huisingh, J., Koppert, P. \& Neumann, F., 1990. Protection of the North Sea: time for clean production. Erasmus Centre for Environmental Studies, Erasmus Univ., Rotterdam, 79 pp.

Backman, M., Huisingh, D., Persson, E. \& Siljebratte, L., 1991. Preventative environmental protection strategy: first results of an experiment in Landskrona, Sweden. In: Prepare. Dutch Ministry of Economic Affairs, Amsterdam, 2B, 113-151.

Birkeland, C., 1974. Interaction between a sea pen and seven of its predators. - Ecol. Monogr. 44, 211-232

Bundesminister für Umwelt, Naturschutz und Reaktorsicherheit (Hrsg.), 1992. Alternatives to organohalogens. Bundesminister für Umwelt, Naturschutz und Reaktorsicherheit, Bonn, $200 \mathrm{pp}$. 
Cadée, G. C., 1990. Increase of Phaeocystis blooms in the westernmost inlet of the Wadden Sea, the Marsdiep, since 1973. In: Eutrophication and algal blooms in North Sea coastal zones, the Baltic and adjoining areas: prediction and assessment of preventive actions. Ed. by C. Lancelot, G. Billen \& H. Barth. Commission of the European Communities, Brussels, 105-112.

Caughley, G. \& Lawton, J. H., 1981. Plant-herbivore systems. In: Theoretical ecology. Ed. by R. M. May, Blackwell, Oxford, 132-166.

Christiansen, K. \& Kryger, J., 1989. Promotion and implementation of cleaner technologies in Danish industries. Centre for Cleaner Technologies, Technological Institute of Copenhagen, Copenhagen, $29 \mathrm{pp}$.

Davies, A. G., Madariaga, I. de, Bautista, B., Fernández, E., Harbour, D.S., Serret, P.\& Tranter P.R. G., 1992. The ecology of a coastal Phaeocystis bloom in the north-western English Channel in 1990. - J. mar. biol. Ass. U. K. 72, 691-708.

Dayton, P. K., 1984. Processes structuring some marine communities: Are they general? In: Ecological communities: conceptual issues and the evidence. Ed. by D. R. Strong, D. Simberloff, L. G. Abele \& A. B. Thistle. Princeton Univ. Press, Princeton, 181-197.

Dayton, P. K., Robilliard, G. A., Paine, R. T. \& Dayton, L. B., 1974. Biological accommodation in the benthic community at McMurdo Sound, Antarctica. - Ecol. Monogr. 44, 105-128.

Dickson, R. R. (Ed.) 1987. Irish Sea status report of the marine pollution monitoring group. - Aquat. environ. Monit. Rep. 17, 7-8.

Dieleman, H., Berkel, R. van, Reijenga, F., Hoo, S. de, Brezet, H., Cramer, J. \& Schot, J., 1991. Choosing for prevention is winning. In: Prepare. Part IIA: Experiences. Dutch Ministry of Economic Affairs, Amsterdam, 2A, 1-112.

Eisma, D. \& Irion, G., 1988. Sediment matter and sediment transport. In: Pollution of the North Sea. Ed. by W. Salomons B. L. Bayne, E. K. Duursma \& U. Förstner. Springer, Berlin, 20-35.

Fox, W., 1990. Towards a transpersonal ecology. Shambhala, Boston, $380 \mathrm{pp}$.

Gaines, S. \& Roughgarden, J., 1985. Larval settlement rate: a leading determinant of structure in an ecological community of the marine intertidal zone. - Proc. natn. Acad. Sci. U.S.A. 82, 3707-3711.

Gerlach, S., 1988. Nutrients - an overview. In: Environmental protection of the North Sea. Ed. by P. J. Newmann \& A. R. Agg. Heinemann, Oxford, 147-175.

Godfray, H. C. J. \& Blyth, S. P., 1990. Complex dynamics in multispecies communities. - Phil. Trans. R. Soc. (Ser. B) 330, 221-233.

Gunkel, W., 1994. 100 years of the Biologische Anstalt Helgoland: a cliff in the North Sea steeped in the tides and currents of history. - Helgoländer Meeresunters. 49, 69-75.

Hansen, F. C., 1994. Trophic interactions between zooplankton and Phaeocystis. - Helgoländer Meeresunters. 49, 281-291.

Harcourt, D. G., 1971. Population dynamics of Leptinotarsa decemlineata (Say) in eastern Ontario. III. Major population processes. - Can. Ent. 103, 1049-1061.

Hargrove, E. C., 1987. Problems and prospects, - Environ. Ethics 9, 195-196.

Hassell, M. P., 1981. Arthropod predator-prey systems. In: Theoretical ecology. Ed. by R. M. May. Blackwell, Oxford, 105-131.

Hoo, S. de, Brezet, H., Crul, M. \& Dieleman, H. (Eds), 1991. Manual for the prevention of waste and emissions. In: Prepare. Dutch Ministry of Economic Affairs, Amsterdam, 1, 1-84.

Hoogweg, P., Ducrotoy, J. \& Wettering, B., 1991. The North Sea Task Force: the first two years. Mar. Pollut. Bull. 22, 328-330.

Huisingh, D., 1989. Cleaner technologies through process modifications, material substitutions and ecologically based ethical values. - Ind. Environ. 12, 4-8.

Hutchingson, G. E., 1961. The paradox of the plankton. - Am. Nat. 95, 137-45

ICES Advisory Committee on Marine Pollution (Ed.), 1985. Biological effects studies. - Rep. ICES Advisory Comm. mar. Pollut. 1984, 17-21.

Irish Sea Study Group (Ed.), 1990. Waste inputs and pollution. Liverpool Univ. Press, Liverpool, 2 , $1-165$.

Johnston, P. \& MacGarvin, M., 1989, 0-2000: assimilating lessons from the past. - Greenpeace Rep. $28,1-32$.

Johnston, P., MacGarvin, M. \& Stringer, R. L., 1990a. Regulation of effluents and implications for environmental policy. - Wat. Sci. Technol. 24, 19-27. 
Johnston, P., Stringer, R. L. \& French, M. C., 1990b. Pollution of UK estuaries: historic and current problems. - Sci. total, Environ. 106, 55-70.

Johnston, P., MacGarvin, M., Stringer, R. L. \& Troendle, S., 1993. Sewage: towards realistic. environmental protection. - Wat. Sci. Technol. 27, 481-491.

Kareiva, P., 1989. Renewing the dialogue between theory and experiments in population ecology. In: Perspectives in ecological theory. Ed. by J. Roughgarden, R. M. May \& S. A. Levin. Princeton Univ. Press, Princeton, 68-88.

Kinne, O., 1994. Ecology of the North Sea: problems, successes, failures, future needs. - Helgoländer Meeresunters. 49, 23-24.

Lancelot, C., Billen, G., Sournia, A., Weisse, T., Colijn, C., Veldhuis, M. J. W., Davies, A. \& Wassman, P., 1987. Phaeocystis blooms and nutrient enrichment in the continental coastal zones of the North Sea. - Ambio 16, 38-46.

Larsen, I. \& Olsen, K. O., 1989. Furthering cleaner technology: the role of decentral authorities. In: 1st International Conference on waste minimisation and clean technology. Internat. Public Works Fed. Working Group on Hazardous Wastes, UNEP, Geneva, 250-262.

Lawton, J. H., 1991. Ecology as she is done, and could be done. - Oikos 61, 289-90.

Lewin, R., 1986. Supply-side ecology. - Science, N.Y. 234, 25-7.

Lindhquist, T., 1989. The environmental product declaration, EPD. UN ECE Seminar on economic implications of low-waste technology (16-19 Oct. 1989). The Hague, Netherlands. 8 pp. (Paper ENVWA/SEM/R.B)

Lothigius, Jan (Ed.), 1991. Toxic organic compounds in the Baltic. - Enviro 11, 1-29 (Special issue).

Lubchenco, J. \& Menge, B. A., 1978. Community diversity and persistence in a low rocky intertidal zone. - Ecol. Monogr. 48, 67-94.

MacGarvin, M. \& Johnston, P., 1993. On precaution, clean production \& paradigm shifts. - Wat. Sci. Technol. 27, 469-480.

MacGarvin, M. \& Johnston, P., 1988. Monitoring annex. In: A submission to the IMSO meeting for the Third North Sea Conference. Greenpeace International, Amsterdam, $27 \mathrm{pp}$.

Mann, K. H. \& Lazier, J. R. N., 1991. Dynamics of marine ecosystems: biological-physical interactions in the oceans. Blackwell, Boston, 466 pp.

McGowan, J. A. \& Walker, P. W., 1979. Structure in the copepod community of the North Pacific central gyre. - Ecol. Monogr. 49, 195-226.

Mclntyre, A. D. \& Pearce, J. B., 1980. Foreword. - Rapp. P.-v. Réun. Cons. int. Explor. Mer. 179, 5.

Menge, B. A., 1976. Organisation of the New England rocky intertidal community: role of predation, competition and environmental heterogeneity. - Ecol. Monogr. 46, 355-393.

Menge, B. A. \& Sutherland, J. P., 1976. Species diversity gradients: synthesis of the roles of predation, competition, and temporal heterogeneity. - Am. Nat. 110, 351-369.

Naes, A., 1989. Ecology, community and lifestyle: outline of an ecosophy. Cambridge Univ. Press, Cambridge, $223 \mathrm{pp}$.

Nirmalakhandan, N. \& Speece, R. E., 1988. Structure-activity relationships. - Environ. Sci. Technol. $22,606-615$.

Oslo \& Paris Commission (Ed.), 1992a. Convention for the protection of the marine environment of the North-East Atlantic. Paris Commission Secretariat, London, $50 \mathrm{pp}$.

Oslo \& Paris Commission (Ed.), 1992b. Action plan of the Oslo \& Paris Commissions, 1992. Oslo \& Paris Commission Secretariat, London, $8 \mathrm{pp}$.

Paine, R. T., 1966. Food web complexity and species diversity. - Am. Nat. 100, 65-75.

Paine, R. T., 1971. A short term experimental investigation of resource partitioning in a New Zealand rocky tidal habitat. - Ecology 52, 1096-1106.

Paine, R. T., 1980, Food webs: linkage, interaction strength and community infrastructure. - J. Anim. Ecol. 49,667-685.

Paris Commission (Ed.), 1991. Report on land-based inputs of contaminants to the waters of the Paris Convention 1989. Paris Commission, London (PARCOM 13/6/3-E).

Pearson, P., 1991. Chlorine is dying: we told you so. - Pulp Paperind. August, 54.

Peterman, R. M. \& M Gonigle, M., 1992. Statistical power analysis and the precautionary principle. Mar. Pollut. Bull. 24, 231-234.

Peters, R. H., 1991. A critique for ecology. Cambridge Univ. Press. Cambridge, 366 pp. 
Puckett, J., 1991. Dumping by another name: the recycling of imported hazardous wastes in Bilbao, Spain by the ASER Company. Greenpeace International, Amsterdam, 68 pp.

Rosander, P. \& Fredman, A., 1989. Clean opportunity - without chlorinated solvents. Greenpeace Sweden, Gothenburg, $30 \mathrm{pp}$.

Rothschild, B. J., 1986. Dynamics of marine fish populations. Harvard Univ. Press, Cambridge, $277 \mathrm{pp}$.

Roughgarden, J., 1989. The structure and assembly of communities. In: Perspectives in ecological theory. Ed. by J. Roughgarden, R. M. May \& S. A. Levin. Princeton Univ. Press, Princeton, 203-226.

Roughgarden, J., May, R. M. \& Levin, S. A. (Eds), 1989. Perspectives in ecological theory. Princeton Univ. Press, Princeton.

Salomons, W., 1988. Heavy metal chemicals - an overview. In: Environmental protection of the North Sea. Ed. by P. J. Newmann \& A. R. Agg. Heinemann, Oxford, 245-255.

Sarokin, D. J., Muir, W. R., Miller, C. G. \& Sperber, S. R., 1985. Cutting chemical wastes: What 29 organic chemical plants are doing to reduce hazardous wastes. Ed. by P. Stryker \& P. Lone. INFORM, New York, 535 pp.

Simberloff, D., 1988. The contribution of population and community biology to conservation science. - A. Rev. Ecol. Syst. 19, 473-511.

Smith, V. J. \& Johnston, P. A., 1992. Differential haemotoxic effects of PCB congeners in common shrimp Crangon crangon. - Comp. Biochem. Physiol. 101C, 641-649.

Sperling, K. R., 1986. Protection of the North Sea: balance and prospects. - Mar. Pollut. Bull. 17, 241-246.

Stebbing, A. R. D., 1992. Environmental capacity and the precautionary principle. - Mar. Pollut. Bull. $24,287-295$

Stebbing, A. R. D., Dethlefsen, V. \& Thurberg, F., 1990. Report on the ICES/IOC North Sea seagoing workshop. In: North Sea pollution: technical strategies for improvement. IAWPRC/EWPCA/ NVA, Amsterdam, 41-45.

Strong, D. R., Simberloff, D., Abele, L. G. \& Thistle, A. B. (Eds), 1984. Ecological communities: conceptual issues and the evidence. Princeton Univ. Press, Princeton, $613 \mathrm{pp}$.

U.S. Environmental Protection Agency (Ed.), 1988. Waste minimisation opportunity assessment manual. US EPA, Cincinnati, $26 \mathrm{pp}$.

Underwood, A. J., 1985. Physical factors and biological interactions: the necessity and nature of ecological experiments. In: The ecology of rocky coasts. Ed. by P. G. Moore \& R. Seed. Hodder \& Stoughton, London, 372-390.

Underwood, A. J. \& Denley, E. J., 1984. Paradigms, explanations and generalisations in models for the structure of intertidal communities on rocky shores. In: Ecological communities: conceptual issues and the evidence. Ed. by D. R. Strong, D. Simberloff, L. G. Abele \& A. B. Thistle. Princeton Univ. Press, Princeton, 151-180.

Underwood, A., Denley, E. \& Moran, M., 1983. Experimental analysis of the structure and dynamics of mid-shore rocky intertidal communities in New South Wales. - Oecologia 56, 202-19.

UNEP Governing Council (Ed.), 1989. Precautionary approach to marine pollution, including waste dumping at sea. In: Proceedings of the fifteenth session, United Nations Governing Council General Council. UNEP, New York, Annex 1, 63-65 (UNEP/GC. 15/12).

Varley, G. C., Gradwell, G. R. \& Hassell, M. P., 1973. Insect population ecology. Blackwell, Oxford, $212 \mathrm{pp}$.

Wootton, R. J., 1990. Ecology of teleost-fishes, Chapman \& Hall, London, 404 pp. 